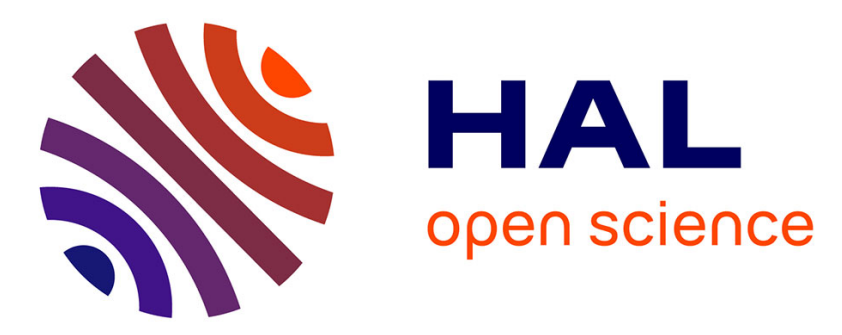

\title{
Influence of Inertial Stimulus on Visuo-Vestibular Cues Conflict for Lateral Dynamics at Driving Simulators
} Baris Aykent, Frédéric Merienne, Damien Paillot, Andras Kemeny

\section{To cite this version:}

Baris Aykent, Frédéric Merienne, Damien Paillot, Andras Kemeny. Influence of Inertial Stimulus on Visuo-Vestibular Cues Conflict for Lateral Dynamics at Driving Simulators. Journal of Ergonomics, 2013, 3 (1), pp.1-8. 10.4172/2165-7556.1000113 . hal-00794925v2

\section{HAL Id: hal-00794925 \\ https://hal.science/hal-00794925v2}

Submitted on 27 Feb 2013

HAL is a multi-disciplinary open access archive for the deposit and dissemination of scientific research documents, whether they are published or not. The documents may come from teaching and research institutions in France or abroad, or from public or private research centers.
L'archive ouverte pluridisciplinaire HAL, est destinée au dépôt et à la diffusion de documents scientifiques de niveau recherche, publiés ou non, émanant des établissements d'enseignement et de recherche français ou étrangers, des laboratoires publics ou privés. 
This is an open-access article distributed under the terms of the Creative Commons Attribution License, which permits unrestricted use, distribution, and reproduction in any medium, provided the original author(s) and source are credited.

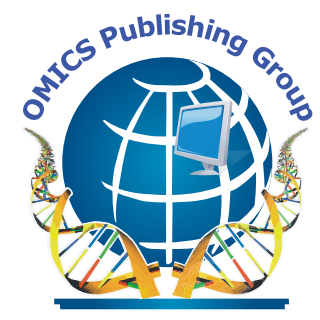

ISSN: 2165-7556

\section{Journal of Ergonomics}

\section{The International Open Access \\ Journal of Ergonomics}

\section{Editor-in-Chief}

Patrick E. Patterson

Texas University, USA

\section{Executive Editors}

\section{Masahiro Tomita}

Mie University, Japan

\section{Larry Fennigkoh}

Milwaukee School of Engineering, USA

Paul Atchley

University of Kansas, USA

Nancy A Nickman

University of Utah, USA

\section{Available online at: OMICS Publishing Group (www.omicsonline.org)}

7 his article was originally published in a journal by OMICS

1 Publishing Group, and the attached copy is provided by OMICS Publishing Group for the author's benefit and for the benefit of the author's institution, for commercial/research/educational use including without limitation use in instruction at your institution, sending it to specific colleagues that you know, and providing a copy to your institution's administrator.

All other uses, reproduction and distribution, including without limitation commercial reprints, selling or licensing copies or access, or posting on open internet sites, your personal or institution's website or repository, are requested to cite properly. 


\title{
Influence of Inertial Stimulus on Visuo-Vestibular Cues Conflict for Lateral Dynamics at Driving Simulators \\ Aykent $B^{1 *}$, Merienne $F^{1}$, Paillot $D^{1}$ and Kemeny $A^{1,2}$
}

${ }^{1}$ CNRS Le2i Arts et Metiers Paris Tech, 2 Rue T. Dumorey, 71100 Chalon sur Saone, France

${ }^{2}$ Technical Centre for Simulation, Renault, Guyancourt, France

\begin{abstract}
This paper explains the effect of having an inertial stimulus (motion platform) for driving simulators on proximity to the reality for the sensed lateral dynamics with respect to the measurements and the perceptual fidelity using a questionnaire technique. To assess this objectively, the vestibular and vehicle level lateral accelerations $\left(a_{y, s e n s e d}=a_{-}\right.$ vest, $\left.a_{y y}=a_{y y e n}\right)$ were saved by using a motion tracking sensor and SCANeR studio software respectively. $\bar{A}$ confidence interval of $95 \%$ was chosen to test the correlations (Pearson's correlation) and to fit models for the distributions of the visual-vestibular lateral accelerations with the multiple linear regression between the conditions of static $(\mathrm{N}=16)$ and dynamic $(\mathrm{N}=21)$ platform cases in terms of visuo-vestibular level lateral accelerations for the group of subjects $(\mathrm{N}=37)$. The results showed that the dynamic platform provides a higher lateral dynamics reality (positive correlation with an incidence of $90.48 \%$ for $\mathrm{N}=21$ ) compared to the static configuration (negative correlation with an incidence of $50 \%$ for $\mathrm{N}=16$ ) from Pearson's correlation and a better fitted model and a lower visuo-vestibular cues' conflict for the dynamic $\left(R^{2}=0.429\right.$, the model is positive sloped, $\left.N=21\right)$ condition comparing to the static one $\left(R^{2}=0.072\right.$, the model is negative sloped, $\left.N=16\right)$ from the multiple linear regression models. $A$ two-tailed Mann Whitney $U$ test yielded that the $U_{\text {computed }}(2139)>U_{\text {expected }}(1300.5)$ as $p<0.0001$, there was a significant difference between the sensed lateral acclerations for the static and dynamic platform cases. Disorientation related perception had positive correlations with the vestibular sensed lateral accelerations for the static condition whereas they were negatively correlated in the dynamic case. As conclusion, the dynamic platform presented a reduced level of motion sickness depending on the sensory conflict theory and the perception fidelity studies approved that dizziness was found to have a significant positive correlation with the vestibular level measured lateral acceleration in the static platform $(r=0.293, p=0.037<0.05)$.
\end{abstract}

Keywords: Driving simulator; Lateral dynamics; Visuo-vestibular interaction; Virtual reality; Sensory cues conflict

\section{Introduction}

Maintaining a sustainable reality of the represented dynamics is a very difficult and sometimes even an impossible issue by using driving simulators. The major leading reasons of this problem are the constrained workspace of the driving simulator and whether a motion platform exists integrated with the driving simulator. The first driving simulators were fixed-base and the simulation was principally only realized by the visual stimulus $[1,2]$ to constitute the self-motion perception. This perception is based on the displacement of visual scene flow on the retina referring to the information about the velocity, direction of the motion and the relative distances [3].

For the static simulator case, illusory self-motion 'vection' often occurs because the driver is stationary and the visual scenario is moving [4-12].

It is obvious that inertial restitution addresses a significant role to maintain a developed fidelity of the driver behaviours on driving simulators. The dynamic simulators are being used since the mid 1960's (Stewart platform) [13] firstly for the flight simulators, then the use has spread to the automotive applications [14-20]. The utilization scope diversifies from driver training to research purposes such as vehicle dynamics control, advanced driving assistance systems (ADAS) [21].

Subjects prefer verbally the dynamic platform rather than the static case [22-25]. Driving simulation sickness was assessed between dynamic and static simulators in some studies [22,26,27]. It was declared that, simulation sickness was coincided lower when using dynamic simulators rather than static simulators respectively $[8,26,27]$. Siegler et al. in 2001 stated that if the motion platform was activated, the bias in reaching increased levels of decelerations was reduced strongly comparing to inactivated platform case for a braking maneuver [28] which was an indicator for avoidance of visuo-vestibular cues conflict. Berger et al. investigated the believability of the forward acceleration on a Stewart motion platform $[18,19]$.

However, there is a lack of publications on reality of lateral dynamics in terms of multi sensory levels (vehicle model: visual lateral acceleration $\mathrm{a}_{\mathrm{vy}}=\mathrm{a}_{\mathrm{y} \text { veh, }}$, motion platform: inertial lateral acceleration, human head level: vestibular lateral acceleration ay_vest=ay, sensed cues). Because of that fact, the reality of lateral dynamics in absence and in presence of the motion platform that yield to two conditions was surveyed in this article.

This paper surveys if there is any correlation between the visuovestibular level accelerations in case of static and dynamic simulators. Visuo-vestibular level accelerations stand for the real-time registered and measured visual and vestibular level accelerations.

Thus it aims to prove the reduction of simulator sickness by using motion platform in terms of visuo-vestibular level acceleration cues proximity (positive correlation).

${ }^{*}$ Corresponding author: Aykent B, CNRS Le2i Arts et Metiers Paris Tech, France, E-mail: b.aykent@gmail.com

Received December 20, 2012; Accepted January 11, 2013; Published January 16,2013

Citation: Aykent B, Merienne F, Paillot D, Kemeny A (2013) Influence of Inertial Stimulus on Visuo-Vestibular Cues Conflict for Lateral Dynamics at Driving Simulators. J Ergonomics 3: 113. doi:10.4172/2165-7556.1000113

Copyright: $\odot 2013$ Aykent B, et al. This is an open-access article distributed unde the terms of the Creative Commons Attribution License, which permits unrestricted use, distribution, and reproduction in any medium, provided the original author and source are credited. 
Here, the visual level acceleration refers to the lateral acceleration values registered from the vehicle model that moves in the visual environment for the driving simulator. Whereas the vestibular level acceleration represents the subjects' head lateral accelerations connected to the right ear by using a head phone.

Also, perception fidelity was investigated by correlating the vestibular level sensed lateral accelerations with the subjective impression which was measured by using the proposed questionnaire.

\section{Materials and Methods}

The research method tackled in this study was to compare the motion platform's contribution on visuo-vestibular acceleration conflicts.

Furthermore the subjects were asked to neither steer the steering wheel nor use the gas, brake pedals and the gear.

The throughout experiment phases were realized as in "virtual driver" mode in the driving simulation software SCANeR studio (Figure 1).

In the data analysis part, the superposition principle of motion was used for evaluating the sensed lateral dynamics at head (vestibular) level (Figures 2 and 5).

The measured lateral acceleration in vestibular level is calculated by equation (1) where

$a_{y, \text { sensed }}:$ Sensed lateral acceleration $\left(\mathrm{m} / \mathrm{s}^{2}\right)$

$a_{y v}:$ Lateral translational acceleration at vestibular level $\left(\mathrm{m} / \mathrm{s}^{2}\right)$

$\varphi$ : Roll angle at vestibular level $\left(^{\circ}\right)$

$g$ : Gravitational acceleration $\left(\mathrm{m} / \mathrm{s}^{2}\right)$

$a_{y, \text { sensed }}=a_{y v} \cdot \cos \varphi+g \cdot \sin \varphi$

$a_{y, \text { sensed }}$ was measured from the participants' right ear levels for the same driven scenario for the static and dynamic platforms via using the sensor in figure 5 .

\section{Dynamic driving simulator}

This research work was performed under the dynamic as well as static operations of the SAAM (Simulateur Automobile Arts et Métiers) driving simulator (Figure 2). The dynamic driving simulator SAAM involves a 6 DOF (degree of freedom) motion system (Figure 3 and table 1) [15]. It is operated on a RENAULT Twingo 2 cabin with the original control instruments (gas, brake pedals, steering wheel). The visual system is realized by a $150^{\circ}$ cylindrical view (Figure 2 ). With the driving cabin of the simulator, the multi-level measuring techniques are available: vehicle model and motion platform dynamics
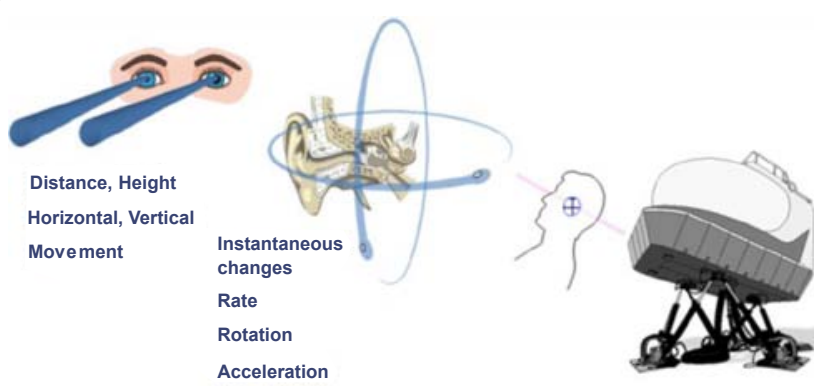

Figure 1: Visuo-vestibular interaction on dynamic driving simulator.

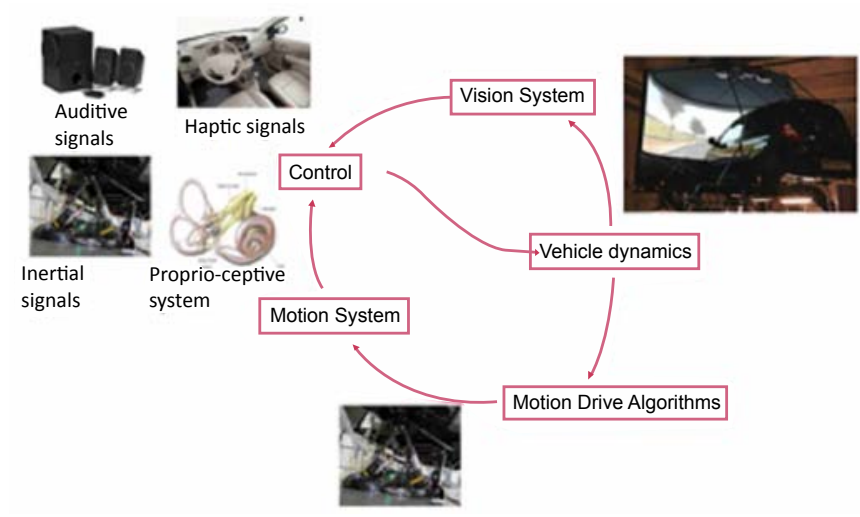

Figure 2: SAAM driving simulator.

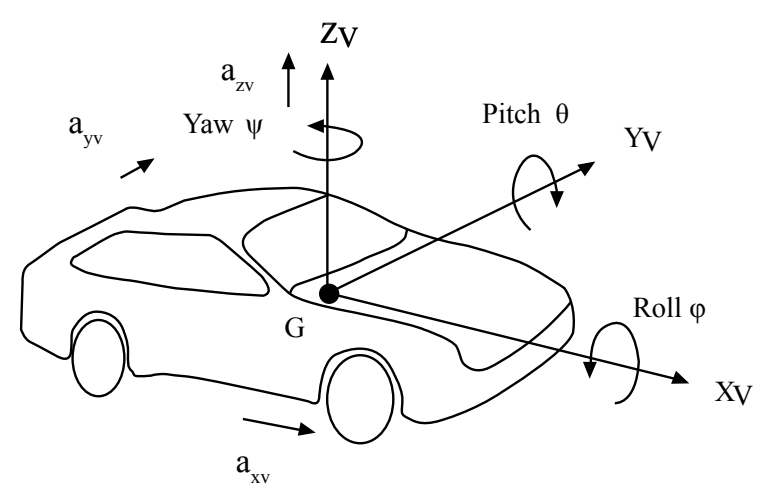

Figure 3: Six degrees of freedom vehicle dynamics.

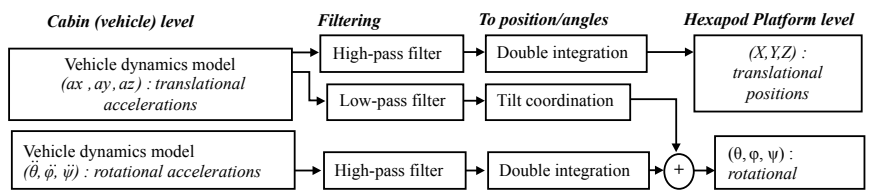

Figure 4: Motion cueing algorithm.

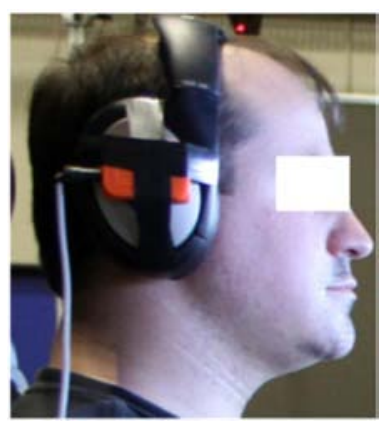

Figure 5: Vestibular level data acquisition.

levels real-time data acquisition via SCANeR studio driving simulation software, vestibular level dynamics real-time data acquisition via XSens motion tracker, arm and neck muscles dynamics measurement via Biopac EMG (electromyography) device, human's center of gravity displacements measuring equipment Technoconcept to check postural stability $[1,29,30]$. 


\begin{tabular}{|c|c|c|c|}
\hline DOF & Displacement & Velocity & Acceleration \\
\hline Pitch & $\pm 22 \mathrm{deg}$ & $\pm 30 \mathrm{deg} / \mathrm{s}$ & $\pm 500 \mathrm{deg} / \mathrm{s}^{2}$ \\
\hline Roll & $\pm 21 \mathrm{deg}$ & $\pm 30 \mathrm{deg} / \mathrm{s}$ & $\pm 500 \mathrm{deg} / \mathrm{s}^{2}$ \\
\hline Yaw & $\pm 22 \mathrm{deg}$ & $\pm 40 \mathrm{deg} / \mathrm{s}$ & $\pm 400 \mathrm{deg} / \mathrm{s}^{2}$ \\
\hline Heave & $\pm 0.18 \mathrm{~m}$ & $\pm 0.30 \mathrm{~m} / \mathrm{s}$ & $\pm 0.5 \mathrm{~g}$ \\
\hline Surge & $\pm 0.25 \mathrm{~m}$ & $\pm 0.5 \mathrm{~m} / \mathrm{s}$ & $\pm 0.6 \mathrm{~g}$ \\
\hline Sway & $\pm 0.25 \mathrm{~m}$ & $\pm 0.5 \mathrm{~m} / \mathrm{s}$ & $\pm 0.6 \mathrm{~g}$ \\
\hline
\end{tabular}

Table 1 and Table 2 give the limits and the classical motion cueing algorithm parameters respectively. DLL plug-in integrated in the software took the constraints of the simulator platform and the classical motion cueing algorithm parameters into account for the dynamic condition.

Table 1: Limits of each degree of freedom (DOF) of the dynamic driving simulator SAAM.

Figure 2 illustrates the SAAM moving-base driving simulator. It could be operated as with static or dynamic platform by switching the "motion platform" module off and on respectively. As seen in the figure, in general there are three dynamical systems of the SAAM driving simulator. They are vehicle dynamics, motion platform dynamics (motion system) and human vestibular dynamics (proprioceptive system). By manipulating or controlling the vehicle dynamics that moves in the vision system and the motion platform dynamics via motion drive algorithms, their effect on human vestibular dynamics can be compared.

In this article, the effect of having an inertial stimulus (motion platform is active and passive separately for the same driving scenario in figures 6 and 7) on human vestibular dynamics and the perception fidelity were discussed [14].

$a_{y, s e n s e d}$ measured to obtain the vestibular level lateral accelerations of the subjects and $\mathrm{a}_{\mathrm{yv}}$, which was given in figure 4 , registered from the vehicle model driven in real-time via the driving simulation software for the same driven scenario for the static and dynamic platforms via using the sensor in figure 5.

Figure 5 describes the motion cueing algorithm used for the dynamic platform condition in this study. The motion cueing algorithm was included in the SCANeR studio driving simulation software via DLL plugin in order to accomplish the real-time driving experiments with the participations of the subjects.

\section{Vestibular level data acquisition}

In order to save the acceleration data from the vestibular level, a motion tracking sensor was used (Figure 5). This motion tracker can measure the data such as the roll, pitch, yaw angles and rates as well as the accelerations in $\mathrm{X}, \mathrm{Y}$ and $\mathrm{Z}$. The data are calibrated due to three dimensional quaternion orientation. The sampling rate for the data registration during the sensor measurements was $20 \mathrm{~Hz}$. For the calibrated data acquisition, the alignment reset was chosen which simply combined the object and the heading reset at a single instant in time. This had the advantage that all co-ordinate systems could be aligned with a single action [16]. The details about the XSens motion tracking sensor are given in [16].

$\mathrm{a}_{\mathrm{y} \text { vest }}$ and $\mathrm{a}_{\mathrm{y} \text {,sensed }}$ are equal to each other and they represent the measurements at the participants' ears as in figure 6 relying on the superposition principle of the translational and the rotational motions based on equation 1 .

\section{Vehicle level data acquisition}

Vehicle level data registered by SCANeR studio software can be splitted as; command data (steering wheel angle, gas, brake pedal input, etc.), motion platform level (translational and angular accelerations of the hexapod platform),vehicle level data (vehicle dynamics, engine, etc.), frequential analysis of the motion platform and vehicle levels (by using FFT (Fast Fourier Transform)).

\section{Protocol}

Two conditions were driven by using "virtual driver". This was a kind of driving of which the driving simulator was driven with "autopilot". In order to achieve this goal, we chose and used a driver handler option that was already appointed as "follow a speed target specified from command data".

The experiment protocol involved two phases of the driving situations as static and dynamic platform conditions on a country road (Figure 6).

Figure 6 also depicts the $\mathrm{X}-\mathrm{Y}$ trajectory which was attempted in the experiment phases. The whole experimental phase was completed with a constant velocity of $60 \mathrm{~km} / \mathrm{h}$ in 126 seconds (Figure 7).

\section{Subjects}

The experimental procedure was done for static and dynamic platform cases. 37 subjects ( $N=37,29$ males and 8 females) participated in experiments.

For the static platform condition, 16 subjects $(\mathrm{N}=16,11$ male and 5 female participants) aged (mean: 33.44 years, SD: 7.66 years) and with driving licence experience (mean : 15.03 years, SD: 7.14 years) participated in this phase (SD: standard deviation).

For the dynamic platform condition, 21 subjects $(\mathrm{N}=21,18$ male and 3 female participants) aged (mean: 31.62 years, SD: 7.33 years) and with driving licence experience (mean: 13.07 years, SD: 6.90 years) participated in this phase (SD: standard deviation).

\section{Data Analysis}

The effect of having an inertial stimulus (motion platform) on
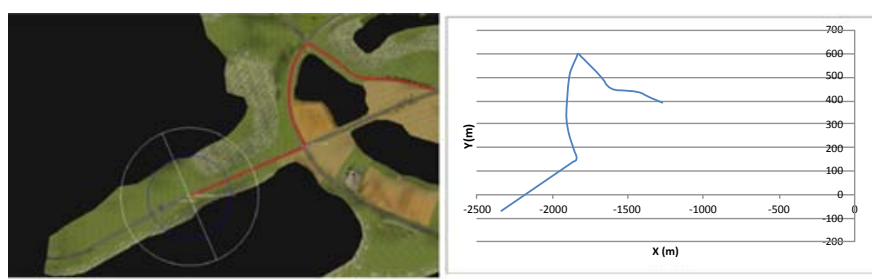

Figure 6: Country road testing land and vehicle CG's (centre of gravity) X-Y trajectory during the experiments.

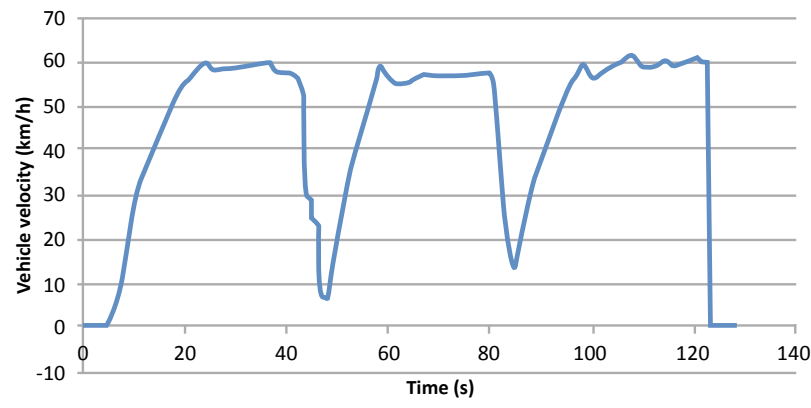

Figure 7: Vehicle velocity during the experiments in virtual driver mode. 
proximity to the reality was discussed here for the sensed lateral dynamics regarding driving simulators.

In order to assess this, the vestibular and vehicle level lateral accelerations $\left(\mathrm{a}_{\mathrm{y}}\right)$ were collected by using a motion tracking sensor (Figure 5) and SCANeR studio software respectively.

Pearson's correlation was computed [18] between the conditions of static and dynamic driving simulator situations in order to assess the visuo-vestibular sensory conflict levels. According this; if the lateral acceleration at vehicle level is negatively correlated to the lateral acceleration at vestibular level, it yields less realistic driving simulation session. And if they are positively correlated with each other, it shows a convergence to the reality. below:

A matlab code example used for the Pearson's correlation is given

* [rvisves, pvisves] =corrcoef (ay_vest_classic_filt, ay_veh_static)

Code $\left({ }^{*}\right)$ shows a matlab code to maintain the correlation coefficients between the vestibular and vehicle level lateral accelerations to establish (Table 3). This process was applied to every single subject and to the both cases.

ay_vest_classic_filt: vestibular level lateral acceleration which was registered at $20 \mathrm{~Hz}$ with classical motion cueing algorithm (dynamic platform)

ay_veh_static: vehicle level lateral acceleration which was registered at $20 \mathrm{~Hz}$

rvisves: correlation coefficient between the vestibular and vehicle level lateral accelerations

pvisves: probability (p-value)

Multiple linear regressions were assigned to evaluate the sensory cue conflict in both situations (Figures 1 and 2) and their difference was compared with a two-tailed Mann-Whitney U test, which is a nonparametric hypothesis test, by using XLSTAT statistics software.

Finally, the subjective evaluations (questionnaire) and objective measurements from the head level $\left(a_{y \text { vest }}=a_{y_{\text {sensed }}}\right)$ were checked in terms of Pearson's correlation coefficient in order to discuss the perception fidelity for the both cases.

\section{Results and Discussion}

In this section, the associations of lateral accelerations on the vehicle and the vestibular levels (Figure 8) and their level of significance were discussed as of having and not having the motion platform during the driving simulator operations.

Figure 8 explained briefly the impact of the inertial stimulus (motion platform) as an example for a subject. The blue curve illustrated the vestibularly sensed lateral acceleration from the experiments which could also be computed from equation 1 . The red curve was depicting the lateral acceleration of the vehicle center of gravity and it was same for the both cases.

Depending on these graphs, it was seen that the lateral acceleration sensed by the vestibular organ indicated a high disparity from the vehicle lateral acceleration between the curvatures (45-105s), during the second curvature turn (105-110s) and the end sections (110-126s) (Figures 6-8) for the static platform condition whereas there was a close match of visuo-vestibular cues for the dynamic platform case.
Moreover between 65-85s. and on the second curvature turn, the high frequent motion was coincided in a higher severity at the vestibular level of the participants for the static platform compared to the dynamic condition (Figure 8).

The visuo-vestibular lateral accelerations' gap reduction during the second curvature turn (105-110s) was sourcing from the onset cueing in general. The close visuo-vestibular lateral acceleration fit in the end sections (110-126s) (Figures 6-8) arose by the tilt coordination and the time delays which were integrated in real-time as seen in figure 4 , tables 1 and 2 for the dynamic platform condition whereas there was a mismatch of visuo-vestibular cues for the static platform case.

Moreover between $65-85 \mathrm{~s}$ and on the second curvature turn, the high frequent motion was coincided in a higher severity at the vestibular level of the participants for the static platform compared to the dynamic condition (Figure 8). The visuo-vestibular lateral accelerations' gap reduction in this period originated from the presence of onset cueing for the dynamic platform case.

Table 3 indicated the impact of the motion platform on the reality of the lateral acceleration. Due to this table, 8 out of the 16 subjects had a negative correlation in terms of 'vestibular lateral accelerationvehicle CG lateral acceleration' who participated in the condition of static platform. Those negative correlations emphasized the sensory cue conflict (50\% of the sensory conflict incidence).

\begin{tabular}{|l|c|c|c|c|c|}
\hline Symbol & Longitudinal & Lateral & Roll & Pitch & Yaw \\
\hline $2^{\text {nd }}$ order LP cut-off frequency $(\mathrm{Hz})$ & & & 0.3 & 0.7 & \\
\hline $2^{\text {nd }}$ order LP damping factor & & & 0.3 & 0.7 & \\
\hline $1^{\text {st }}$ order LP time constant $(s)$ & 0.1 & 0.1 & & & 0.1 \\
\hline $2^{\text {nd }}$ order HP cut-off frequency $(\mathrm{Hz})$ & 0.5 & 0.5 & & & 2 \\
\hline $2^{\text {nd }}$ order HP damping factor & 1 & 1 & & & 1 \\
\hline $1^{\text {st }}$ order HP time constant $(\mathrm{s})$ & 2 & 2 & & & 2 \\
\hline
\end{tabular}

Table 2: Classical Motion cueing algorithm parameters.

\begin{tabular}{|c|c|c|}
\hline $\begin{array}{l}\text { Static condition } \\
\text { Correlation of vestibular lateral } \\
\text { acceleration-vehicle CG lateral acceleration }\end{array}$ & $\begin{array}{l}\text { Dynamic condition } \\
\text { Correlation of vestibular } \\
\text { lateral acceleration-vehicle } \\
\text { CG lateral acceleration }\end{array}$ \\
\hline \multicolumn{2}{|c|}{ Subject 1 } & $\boldsymbol{r}$ \\
\hline Subject 2 & 0.2526 & 0.5441 \\
\hline Subject 3 & -0.5182 & 0.5631 \\
\hline Subject 4 & 0.2088 & 0.5622 \\
\hline Subject 5 & -0.3482 & -0.3482 \\
\hline Subject 6 & -0.3868 & 0.3197 \\
\hline Subject 7 & 0.0554 & 0.5775 \\
\hline Subject 8 & -0.0638 & 0.2091 \\
\hline Subject 9 & -0.2779 & -0.1919 \\
\hline Subject 10 & 0.4647 & 0.6512 \\
\hline Subject 11 & -0.1670 & 0.2149 \\
\hline Subject 12 & -0.0579 & 0.6596 \\
\hline Subject 13 & 0.0779 & 0.2555 \\
\hline Subject 14 & 0.0743 & 0.6227 \\
\hline Subject 15 & 0.1590 & 0.6702 \\
\hline Subject 16 & 0.0756 & 0.4458 \\
\hline Subject 17 & -0.0157 & 0.2651 \\
\hline Subject 18 & & 0.5941 \\
\hline Subject 19 & & 0.5664 \\
\hline Subject 20 & & 0.6036 \\
\hline Subject 21 & & 0.6165 \\
\hline
\end{tabular}

Table 3: Effect of inertial condition on lateral dynamics reality. 
Citation: Aykent B, Merienne F, Paillot D, Kemeny A (2013) Influence of Inertial Stimulus on Visuo-Vestibular Cues Conflict for Lateral Dynamics at Driving Simulators. J Ergonomics 3: 113. doi:10.4172/2165-7556.1000113

Page 5 of 7

Due to this table, 8 out of the 16 subjects had a positive correlation ( $50 \%$ of the sensory conflict avoidance incidence) for the static platform. It meant that; apart from this subject, the rest of them yielded a sensory conflict (negative correlation between vestibular lateral acceleration and vehicle CG lateral acceleration) and divergence from the reality of the lateral dynamics represented on the driving simulator.

For the dynamic case, 19 out of the 21 subjects showed positive correlation. It gave an incidence of $90.48 \%$ for avoiding the sensory cue conflict based motion sickness. For the dynamic platform situation, there was only 2 people who indicated a negative correlation. It can be interpreted as a visuo-vestibular sensory conflict with an incidence of $9.52 \%$.

The negative correlations between visual and vestibular lateral accelerations in the static case were based on the higher level of the lateral head movements which could be realized to compensate the lack of the motion platform influence. In other words, it allowed the gap to increase between visual and vestibular level lateral accelerations when the vehicle level lateral accelerations were the identical for the boths cases (Figure 8 and table 3 ).
Figure 9 illustrated the reality of the lateral dynamics depending on the effect of the inertial cues (motion platform) which were given in figure 1. Figure 9 was also a filled contour mapping for the data yielded in table 3.

These graphs were depicted with respect to the Pearson's correlation coefficients $(r)$. When the correlation coefficient $r$ was near to "1 (red colour)", it meant that the driving simulation was representing the lateral acceleration more real. In other words, it presented less contradicting visuo-vestibular cues as from lateral acceleration in accordance with sensory cue conflict theory. In contrast; when the $r$ was closer to "-1 (blue colour)", it indicated that the lateral dynamics was represented less realistically. Therefore, higher values of discrepancy were resulted between the lateral accelerations values measured from vehicle (visual cue) and vestibular cue levels.

Code $\left(^{* *}\right)$ depicted how figure 9 was created in MATLAB in order to check visuo-vestibular accelerations conflict for the static and dynamic operations of the platform by utilizing the registered data from the SCANeR software.

${ }^{* *}$ contourf ([rvisves, rvisves $_{2}$, rvisves $_{3}, \ldots$, rvisves $\left.\left._{\mathrm{n}}\right]\right)$

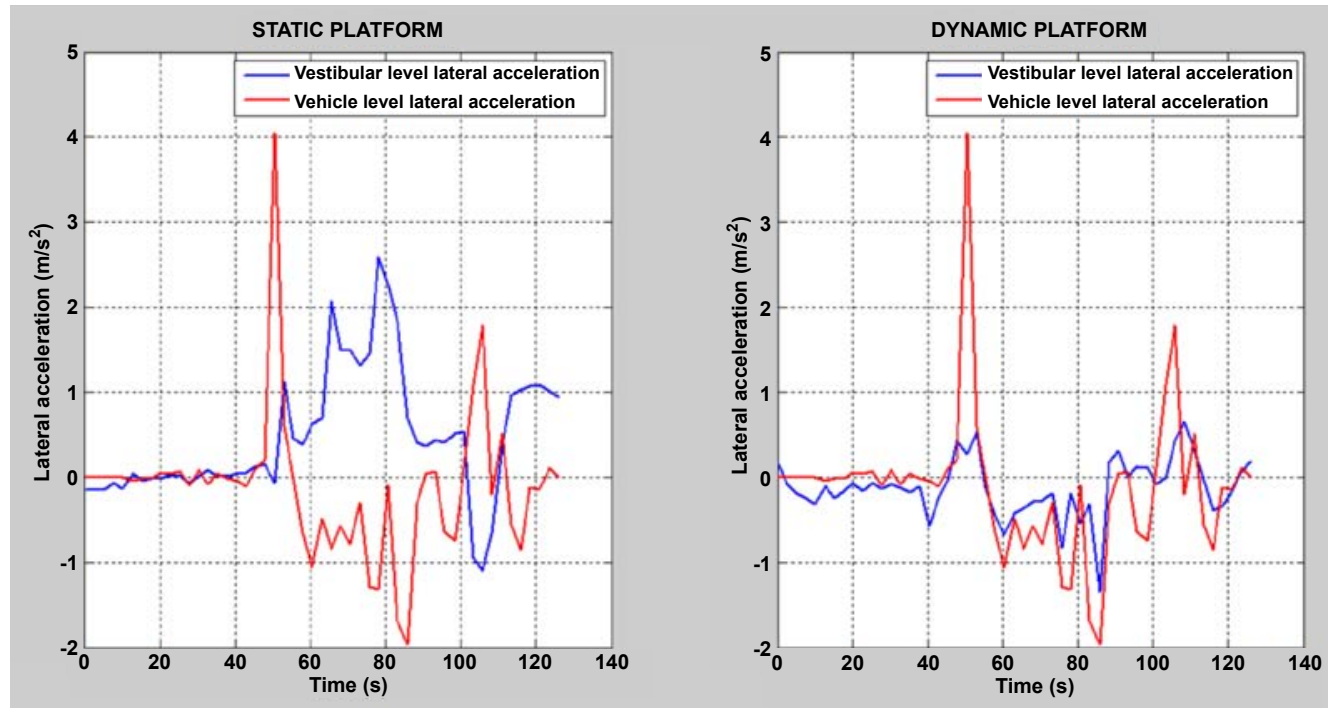

Figure 8: Vehicle-vestibular level lateral accelerations at static and dynamic conditions.

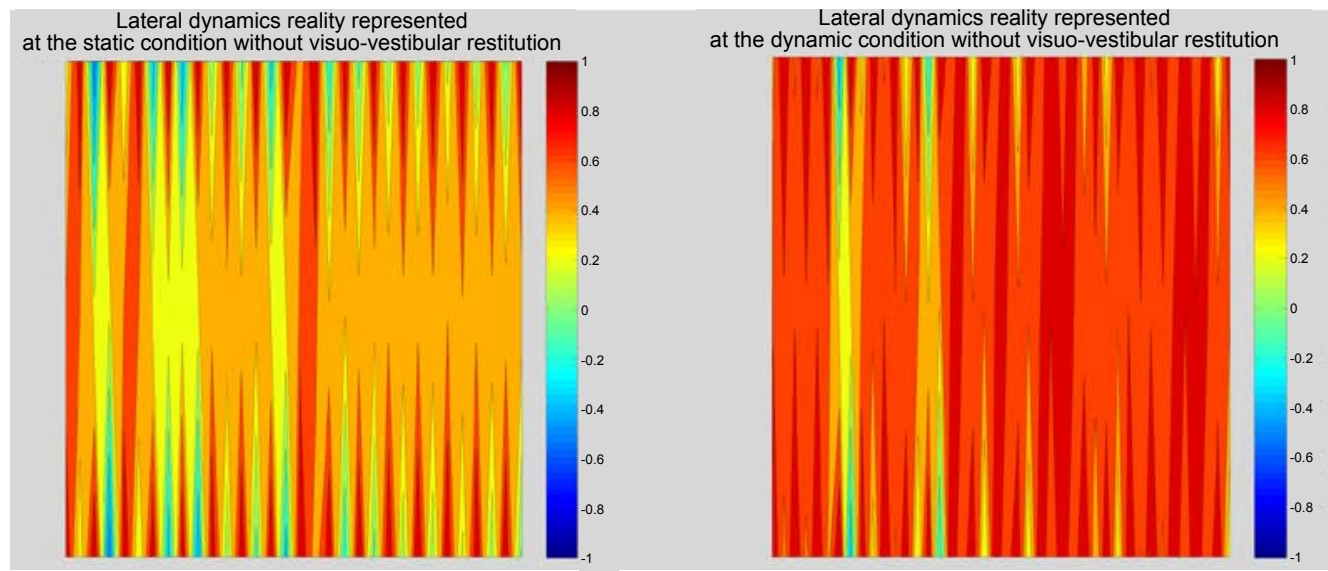

Figure 9: Reality of lateral dynamics depending on the coupling effect. 
$N$ : number of the subjects participated in the experiments.

rvisves $_{1,2, \ldots, \mathrm{N}}$ : correlation coefficient between the vestibular and vehicle level lateral accelerations by individual participants.

A multiple linear regression with a confidence interval of $95 \%$, where the input is the lateral acceleration at visual cues (vehicle lateral acceleration) and the output is the lateral acceleration at vestibular cues (sensed lateral acceleration, Equation 1, was modelled for the static and the dynamic platform cases.

Equation 2 gives the linear regression model for the static platform condition.

$$
a_{y_{-} \text {vest_s }}=-4.62 * 10^{-2}-3.36 * 10^{-2} * a_{y_{-} \text {veh }}
$$

Equation 3 gives the linear regression model for the dynamic platform condition.

$$
a_{y_{-} \text {vest } d}=-0.23+0.20 * a_{y_{-} \text {veh }}
$$

Figure 10 shows the cue conflict comparison of the both cases for the groups of the subjects. Blue dots indicate the real data for the visual and vestibular acceleration cues which were saved from the right ear level of the subjects and the vehicle model driven. Black continuous lines depict the linear regression models. Grey continuous and dashed lines illustrate the confidence interval of $95 \%$ for the mean and the observed values respectively.

According to figure 10, it can be seen that the real data were distributed far from the fitted model line (the coefficient of determination $\mathrm{R}^{2}=0.072$ ) for the static platform. On the other hand, the real data were more closely gathered to the estimated model line (the coefficient of determination $\mathrm{R}^{2}=0.429$ ) for the dynamic platform. Furthermore, it is resulted that the visual lateral accelerations (realtime vehicle model in SCANeR studio software) are getting closer (the slope of the model is positive: inclined to right hand side) to the vestibular lateral accelerations (real-time XSens record as a module in SCANeR studio software) for the dynamic situation.

Inversely, the visuo-vestibular lateral accelerations are getting far away from each other (the inclination of the model is negative: inclined to left hand side) which mean that the visuo-vestibular cue conflict are increasing.

Lastly, it is yielded that as the $\mathrm{U}$ (2139) $>\mathrm{U}_{\text {expected }}(1300.5)$ and the computed $\mathrm{p}$-value $(\mathrm{p}<0.0001)$ is lower than the significance level alpha $=0.05$, one should reject the null hypothesis $\mathrm{H} 0$, and accept the alternative hypothesis $\mathrm{Ha}$ after applying the two-tailed Mann-Whitney $\mathrm{U}$ test to check the difference significancy between the static and dynamic situations of the vestibular level sensed lateral accelerations where the tested hypotheses were given below:

H0: The difference of location between the samples from the static $(\mathrm{N}=16)$ and the dynamic $(\mathrm{N}=21)$ cases is equal to 0 .

Ha: The difference of location between the samples from the static $(\mathrm{N}=16)$ and the dynamic $(\mathrm{N}=21)$ cases is different from 0 .

In this research, also the perception fidelity was compared for the two conditions. In order to achieve this goal, Pearson's correlation method was benefited. Three questions were given to the subjects and they were asked to fill in depending on what they perceived during each driving session. The questions regarding the motion sickness (disorientation related) were composed of as the following: Q1- Were you at the point to vomit? Q2- Have you felt nausea? Q3- Have you felt dizziness?

The answers were scaled in equal ten parts as from 1: too little to 10: too strong.

Due to table 4 , it can be seen that the $a_{y_{\text {_vest_sta }}}$ (vestibular level lateral acceleration at static motion platform) was positively correlated $(\mathrm{r}=0.143, \mathrm{p}=0.318$ and $\mathrm{r}=0.056, \mathrm{p}=0.695$ between the sensed lateral acceleration and the propensity to vomit, feeling nausea respectively) with the disorientation related subjective evaluations whereas the $a_{y}$ vest_dyn (vestibular level lateral acceleration at dynamic motion platform) was negatively correlated $(\mathrm{r}=-0.114, \mathrm{p}=0.424 ; \mathrm{r}=-0.119, \mathrm{p}=0.407$ and $\mathrm{r}=-0.143, \mathrm{p}=0.318$ between the sensed lateral acceleration and the propensity to vomit, feeling nausea, feeling dizziness respectively) with the subjective perceptions. In general, it shows that the perception proximity to the measured vestibular level lateral accelerations $\left(a_{y \text { vest }}\right)$ was coincided for the static case rather than the dynamic one. Because the visuo-vestibular sensorial cue conflict increased at the static hexapod platform compared to the dynamic one (Table 4 and figures 8-10). In particular, merely the dizziness feeling had a significant positive correlation $(\mathrm{r}=0.293, \mathrm{p}=0.037<0.05)$ with the sensed lateral acceleration at the static condition.

\section{Conclusion and Future Work}

The reality of the represented lateral dynamics on driving
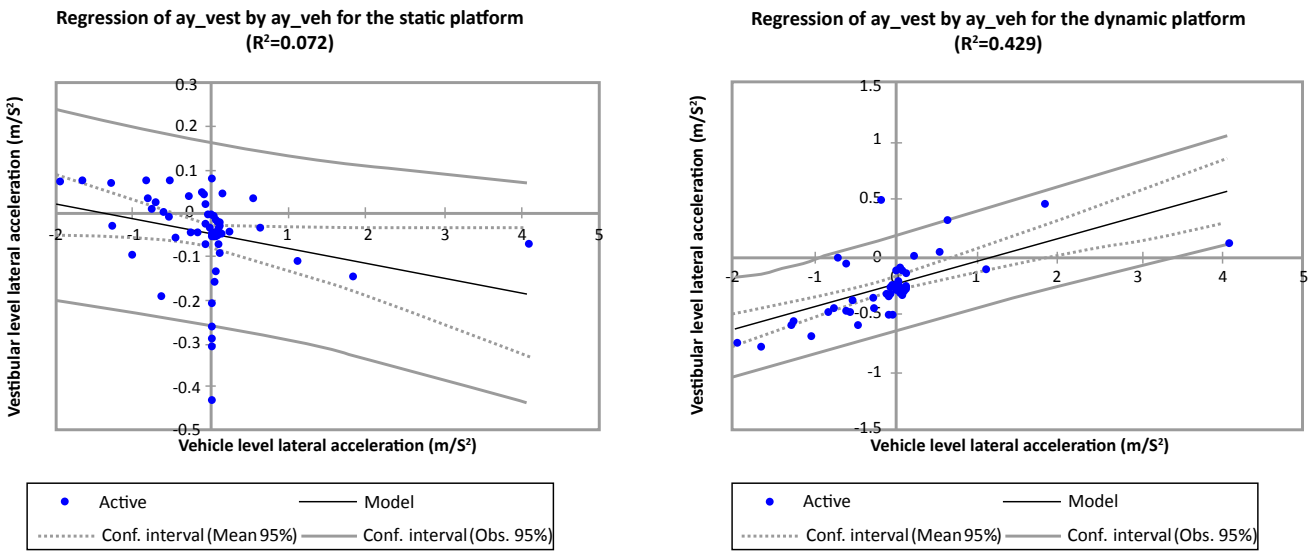

Figure 10: Multiple linear regression models of visuo-vestibular lateral accelerations for static $(\mathrm{N}=16)$ and dynamic $(\mathrm{N}=21)$ platforms. 
Citation: Aykent B, Merienne F, Paillot D, Kemeny A (2013) Influence of Inertial Stimulus on Visuo-Vestibular Cues Conflict for Lateral Dynamics at Driving Simulators. J Ergonomics 3: 113. doi:10.4172/2165-7556.1000113

Page 7 of 7

\begin{tabular}{|c|c|c|c|c|c|c|c|}
\hline \multicolumn{4}{|c|}{ Static motion platform $(\mathrm{N}=16)$} & \multicolumn{4}{|c|}{ Dynamic motion platform $(\mathrm{N}=21)$} \\
\hline Variables & Q1 & Q2 & Q3 & Variables & Q1 & Q2 & Q3 \\
\hline$a_{y}$ vest sta & $0.143(p=0.318)$ & $0.056(p=0.695)$ & $0.293(p=0.037)$ & $a_{y \text { vest } d}$ & $-0.114(p=0.424)$ & $-0.119(p=0.407)$ & $-0.143(p=0.318)$ \\
\hline
\end{tabular}

Values in bold are different from 0 with a significance level alpha $=0.05$

$\mathrm{Q} 1, \mathrm{Q} 2 \mathrm{~s}, \mathrm{Q}{ }_{\mathrm{s}}$ were the answers given by the participants to the questions of $\mathrm{Q} 1, \mathrm{Q} 2$ and $\mathrm{Q} 3$ at the static platform experiments.

$\mathrm{Q} 1_{\mathrm{d}}, \mathrm{Q2} \mathrm{d}_{\mathrm{d}}, \mathrm{Q}$ 3 $_{\mathrm{d}}$ were the answers given by the participants to the questions of Q1, Q2 and Q3 at the dynamic platform experiments.

Table 4: Effect of inertial condition on lateral dynamics reality in absence of Visuo-vestibular restitution.

simulators was discussed in this paper. After having completed these experimental phases, due to the Pearson's correlations, it was proved that the dynamic platform provided a closer lateral dynamics representation between real-time vehicle model (visual cues) and realtime vestibular cues levels. It can be concluded that having dynamic platform represented a higher lateral dynamics reality in terms of data acquisition and measurements. For the dynamic case, there was a positive correlation with an incidence of $90.48 \%$ for $\mathrm{N}=21$, whereas a negative correlation with an incidence of $50 \%$ for $\mathrm{N}=16$ was yielded for the static one.

The multiple linear regression model resulted as a better fit and a positive slope for the visual-vestibular lateral accelerations for the dynamic $\left(\mathrm{R}^{2}=0.429, \mathrm{~N}=21\right)$ platform, whereas it was yielded as a weak fit and a negative slope for the visual-vestibular accelerations for the static $\left(\mathrm{R}^{2}=0.072, \mathrm{~N}=16\right)$ platform.

The two-tailed Mann-Whitney $U$ test proved that there was a significant difference between the static and the dynamic cases in terms of the vestibular level lateral accelerations ( $U_{\text {computed }}(2139)>U_{\text {exp }}$ (1300.5), $\mathrm{p}<0.0001)$.

The perception fidelity illuminated that there was a significant positive correlation $(\mathrm{r}=0.293, \mathrm{p}=0.037<0.05)$ between the vestibular level accelerations and feeling dizziness for the static platform simulator whereas there was no significant correlation between the vestibular level accelerations and the disorientation perception.

As prospective researches, the reality of having motion cueing algorithms with feedback control will be surveyed in terms of multisensory level dynamics approach (neuromuscular cues (EMGelectromyography), visual cues (vehicle level), vestibular cues (head level), inertial cues (motion platform level)) and with respect to postural stability.

\section{References}

1. Stratulat AM, Roussarie V, Vercher JL, Bourdin C (2011) Does tilt/translation ratio affect perception of deceleration in driving simulators? J Vestib Res 21: 127-139.

2. Bertin RJ, Berthoz A (2004) Visuo-vestibular interaction in the reconstruction of travelled trajectories. Exp Brain Res 154: 11-21.

3. Bremmer F, Kubischik M, Pekel M, Lappe M, Hoffmann KP (1999) Linear vestibular self-motion signals in monkey medial superior temporal area. Ann $\mathrm{N}$ Y Acad Sci 871: 272-281

4. Lepecq JC, De Waele C, Mertz-Josse S, Teyssèdre C, Huy PT, et al. (2006) Galvanic vestibular stimulation modifies vection paths in healthy subjects. J Neurophysiol 95: 3199-3207.

5. Kolasinski E (1995) Simulator sickness in virtual environments. DTIC Document, US Army Research Institute for the Behavoral and Social Sciences.

6. Berthoz A, Pavard B, Young L (1975) Perception of linear horizontal self-motion induced by peripheral vision (linearvection) basic characteristics and visualvestibular interactions. Exp Brain Res 23: 471-489.

7. DiZio P, Lackner J (1989) Perceived self-motion elicited by postrotary head tilts in a varying gravitoinertial force background. Percept Psychophys 46: 114-118.

8. Draper MH (1998) The adaptive effects of virtual interfaces: vestibulo-ocular reflex and simulator sickness. University of Washington.
9. Hettinger LJ, Berbaum KS, Kennedy RS, Dunlap WP, Nolan MD (1990) Vection and simulator sickness. Mil Psychol 2: 171-181.

10. Hettinger LJ, Ricco GE (1992) Virtually induced motion sickness in virtual environments. Presence-Teleop Virt 1: 306-310

11. Hettinger LJ (2002) Illusory self-motion in virtual environments. Handbook of virtual environments Design implementation and applications.

12. McCauley ME, Sharkey TJ (1992) Cybersickness- perception of self-motion in virtual environments. Presence-Teleop Virt 1: 311-318.

13. Stewart D (1965) A platform with six degrees of freedom. Proceedings of the Institution of Mechanical Engineers 180: 371-386.

14. Haro E, Basset M, Caroux J (2009) Multi-structure approach for complex systems identification. Mechatronics 6: 1003-1015.

15. Aykent B, Paillot D, Mérienne F, Fang Z, Kemeny A (2011) Study of the influence of different washout algorithms on simulator sickness for a driving simulation task. ASME 2011 World Conference on Innovative Virtual Reality.

16. XSens Technologies BV 15 (2010) MTi and MTx User Manual and Technical Documentation. Document MT0100P, Revision O.

17. Statistics Toolbox User's Guide (2003) MathWorks: Natick, MA

18. Berger DR, Schulte-Pelkum J, Bülthoff $\mathrm{HH}$ (2010) Simulating believable forward accelerations on a stewart motion platform. ACM Trans Appl Percept 7: 1-5.

19. Berger D, Schulte-Pelkum J, Bülthoff H (2007) Simulating believable forward accelerations on a stewart motion platform, Max Planck Institute for Biological Cybernetics.

20. Oman CM (1990) Motion sickness: a synthesis and evaluation of the sensory conflict theory. Canadian J Physiol Pharmacol 68: 294-303.

21. Meywerk M, Aykent B, Tomaske W (2009) Einfluss der Fahrdynamikregelung au die Sicherheit von N1-Fahrzeugen bei unterschiedlichen Beladungszuständen. (Teil 1: Grundlagen, Unfallstatistik, Abstütz- und Beladungseinrichtung, Fahrzeugdatenermittlung. FE 82.329/2007).

22. Colombet F, Dagdelen M, Reymond G, Pere C, Merienne F, et al. (2008) Motion cueing: What is the impact on the driver's behavior, DSC 2008 Monaco.

23. Parrish RV, Martin DJ (1976) Comparison of a linear and a non linear washout for motion simulator utilizing objective and subjective data from transport landing approaches. Tech Rep NASA.

24. Reid L, Nahon M (1990) Simulator Motion-Drive algorithms: a designer's perspective. Journal of Guidance 13: 356-362

25. Hall JR (1989) The need for platform motion in modern piloted flight training simulators. Tech Mem: FM 35.

26. Curry R, Artz B, Cathey L, Grant P, Greenberg J (2002) Kennedy ssq results: fixed-vs. motion-based FORD simulators. Proceedings of DSC: 289-300.

27. Watson GS (2000) A Synthesis of Simulator Sickness Studies Conducted in a High-Fidelity Driving Simulator. Proceedings of Driving Simulation Conference.

28. Siegler I, Reymond G, Kemeny A, Berthoz A (2001) Sensorimotor integration in a driving simulator: contributions of motion cueing in elementary driving tasks, DSC, Sophia Antipolis.

29. Aykent B, Paillot D, Merienne F, Kemeny A (2012) The Influence of the feedback control of the hexapod platform of the SAAM dynamic driving simulator on neuromuscular dynamics of the drivers. Driving Simulation Conference, Paris France.

30. Aykent B, Paillot D, Merienne F, Kemeny A (2012) A LQR Washout Algorithm for a Driving Simulator Equipped with a Hexapod Platform: The Relationship of Neuromuscular Dynamics with the Sensed Illness Rating. CONFERE, Venice, Italy. 